\title{
Investigation on the Decomposition Work Process of Public Hospitals in Harbin
}

\author{
Shu-jun CHEN \\ Harbin University of Commerce, \\ School of Public Finance and Administration \\ Harbin ,China \\ ldyshbz@126.com
}

\author{
Yu-wen $\mathrm{CHI}^{*}$ \\ Harbin University of Commerce, \\ School of Public Finance and Administration \\ Harbin, China \\ 15846510857@163.com
}

\begin{abstract}
With the deepening of urban public hospital reform, the long-term liabilities of public hospitals have become an urgent problem for the government. This article takes Harbin as an example, analyzes the current situation of the debt relief process in public hospitals in Harbin. Based on the city's own economic situation, debt structure and the causes of debt formation, this paper discusses the problems of financial support, supervision mechanism of health administrative departments and internal economic management of hospitals, then puts forward relevant countermeasures.
\end{abstract}

Keywords-Urban public hospitals; Debt management; Public welfare; Financial support

\section{INTRODUCTION}

Since the country deepened the reform of the medical and health system, a large amount of financial funds flowed to public hospitals to solve the shortage of medical resources and improve the quality of medical services. Yet,it is still common for public hospitals to be run in debt. For example, the reason for the high historical debt of public hospitals in Harbin is that the state has increased investment in medical and health care during the Twelfth Five-Year Plan period. However, the amount of investment in the central and provincial planning is limited, and the municipal-level matching funds are insufficient due to the lack of local financial resources. Municipal public medical institutions can only use the bank loans to raise funds for capital construction, purchase large medical equipment and temporarily borrow working capital. Until the end of December 2017, the total liabilities of the fourteen municipal public hospitals totaled 3.318 billion Yuan, asset-liability ratio reached $56.73 \%$.Among them, long-term liabilities were 1.032 billion yuan and current liabilities were 2.286 billion yuan. Among the long-term liabilities, 696 million yuan from four hospitals including Harbin First Hospital, Harbin Second Hospital, Harbin Fourth Hospital and Harbin Fifth Hospital have been included in the government debt platform. In the current liabilities, the drug owed 807 million Yuan, short-term loans 296 million yuan, medical supplies owed 659 million yuan, and other accounts payable 524 million Yuan. If the huge debt problem cannot be solved in time, not only the comprehensive reform of urban public hospitals will be seriously hindered, but also the reform process of China's medical and health system will be affected. At present, debt

This work is supported by Social Science Foundation of Heilongjiang Province under Grant 16RKD01.

This work is supported by Harbin University of Commerce graduate student innovation research project under YJSCX2018-496HSD. resolution has become the focus of public hospital reform.

Currently, a large number of scholars have had a heated discussion on the causes of debt formation in public hospitals. Cao Jian, a researcher at Tsinghua University Medical Management Research Center, researched that from the assetliability ratio, it can be seen that the development of most public hospitals does not rely on the accumulation of the hospital's own balance of income and expenditure and the support of the government's financial funds, but relies on its own continuous borrowing for development [1].Faced with the huge debt burden, public hospitals have to start to pursue profits, which is not conducive to the realization of their public welfare functions, but also makes hospitals fall into a vicious circle of development. Zhigang Sun, director of the Medical Reform Office of the State Council, pointed out that long-term debt is the product of the "medical supplementation" mechanism that compensation system for the medical cost through drug-selling profits [2]. Xiaohui Lu of the National Audit Office found that most of the hospital debt is the cost of its own infrastructure and large equipment [3]. Shaolong Wu believes that the government has encouraged public hospitals to "self-support" since the opening of the market economy in the 1980s,driven by market competition, public hospitals choose to attract more patients through equipment competition in order to seek development and growth[4]. The first to comment on the debt settlement is the Anhui Provincial Government, put forward a variety of ways, including the use of creditor's rights replacement, financial subsidies, self-raised funds, negotiation and negotiation, and policy support, to effectively solve the problem of public hospital debt. Xiangxiang Wang of Wuhu City Hospital of Traditional Chinese Medicine in Anhui Province proposed that the financial compensation method for the decommissioning work of public hospitals in Wuhu City is relatively simple, inefficient, and the scale of compensation needs to be improved He suggested that the financial compensation system should be improved and a financial compensation and supervision mechanism should be established [5]. Yiping Qi proposed that the debt relief work of urban public hospitals in Jiangxi Province should be given priority to resolve the debts of hospitals with heavier debts and poor profitability. And clean up and audit the debt, analyze the profit and loss situation, and clarify the responsibility[6].Overall, domestic scholars have little research on the debt relief work of public hospitals in 
Harbin, and there are no systematic research results. Based on this, this paper will conduct research on the progress of debt relief work in public hospitals in Harbin.

\section{CurRent SituAtion AND PROBlems OF DEBT RESOLVING WORK IN HARBIN PUBLIC HOSPITALS}

\section{A. Current situation of debt relief work in public hospitals in Harbin}

As a government-run hospital, public hospitals have the public welfare and security of providing medical services to the society. This also determines the responsibility of the government to resolve the debts of public hospitals. However, since Harbin is a less developed city in China, the financial repayment ability is far less than that of developed regions such as Guangzhou and Shanghai. Therefore, the Harbin municipal government cannot pay all the debts. At present, the Harbin Municipal Health Planning Commission has proposed the following three measures for the debt problems of fourteen public hospitals.

1) Negotiating for support from Ministry of finance: The liabilities included in the government debt platform and Israeli loans of 786 million yuan, drawing on the practices of cities such as Shanghai, Shenzhen, Hangzhou and Xiamen, increasing financial support, implementing government input responsibilities, and arranging special funds every year by the municipal finance Public hospital debt.

2) Negotiating replacement credits with Industrial Bank: Recently, as the Harbin Municipal Health Planning Commission plans to launch a GPO drug procurement model, it will increase the pressure on municipal hospitals to repay their arrears in the short term. Public hospitals are no longer allowed to generate new long-term liabilities due to policy restrictions. So, Industrial Bank promises to provide a three-year short-term loan with the best interest rate.

3) Strengthen management and resolve some debts on its own: The Harbin Municipal Health Planning Commission put forward stricter requirements for hospital management at the meeting of party and government leaders of municipal public hospitals. Including strengthen the internal management of the hospital, report on major issues decision-making, appointment and removal of important cadres, major project investment decisions, and use of large amounts of funds. Resolving the current liabilities of 11.13 billion yuan by improving the level of refined management of hospitals, strengthening cost accounting, and optimizing revenue and expenditure structure, etc.

\section{B. Problems of debt relief work in public hospitals in Harbin}

1) Weak financial support: Shanghai has started municipal debt restructuring in Shanghai in 2011.And Shanghai Municipal Finance arranged 771.92 million yuan and 810.65 million yuan in 2011 and 2012 respectively to complete the task of capital construction in the "10th FiveYear Plan" period. Thanks to the different degrees of economic development, the debts of public hospitals in Harbin cannot be solved by the municipal finance. Nevertheless, strengthening government responsibility is not only one of the six key tasks in the reform of the medical and health system, but also the key task of the Harbin Urban Public Hospital Comprehensive Reform Implementation Plan. The plan clearly states that governments at all levels should implement government input responsibilities, gradually repay and resolve longterm debts of public hospitals that meet the requirements. But, the government did not make standard regular capital investment plans in the actual work process, resulting the lack of protection of the funds used to resolve the debt. This will directly affect the accuracy of financial support and the timeliness of debt repayment.

2) Lack of supervision in the health administration: Whether it is the use of funds supported by the government or the process of self-solving debts by the hospital, the health administrative department has regulatory responsibility. On the one hand, if the funds for financial support cannot be effectively supervised, this approach cannot completely shake off the vicious circle of debt management in public hospitals. On the other hand, as a public welfare second-class institution, public hospitals are different from government departments with relatively fixed performance, and they are also very different from business for profit[7]. How to conduct real-time supervision of the hospital's debt repayment process is the core issue of debt repayment work, avoiding the hospital indirectly transferring debt to patients.

3) Internal economic management of hospital needs to be improved:

- First, under normal circumstances, public hospital deans are good at medicine rather than management, which also leads to their lack of management experience, and does not pay attention to the financial risks caused by debt.

- Second, in order to achieve more performance, the president of public hospitals neglected the hospital's own economic conditions, blindly expanded the scale of debt, and adopted extensive management, which caused resources. Waste is also difficult to resolve the debt problem. This causes both waste of resources and debt problems.

- Third, in China, cadres without major negligence are usually do not be demoted in examination. Many 
public hospital directors are reluctant to pay off debts left by their predecessors during their limited tenure. If public hospitals can't achieve lean formula management, the debt of public hospitals will be difficult to control.

\section{CONCLUSIONS AND SUGGESTIONS}

\section{A. Increase the investment of financial resources.}

Under the comprehensive reform of Harbin City Public Hospital, measures such as eliminating drug additions and reducing medical consumables have reduced the profitability of public hospitals, leading to the debt service of public hospitals is very difficult. Therefore, the government must increase investment to help public hospitals solve long-term debt problems without affecting daily operations. The municipal finance should establish a special fund compensation mechanism so that the scope of compensation is no longer dynamic and formalization, but the financial subsidy standard with a fixed-rated plan, providing institutional guarantee for the debt relief work of public hospitals.

\section{B. Improve the regulatory mechanism:}

The government should implement the medical reform requirements that distinguish the management of hospitals and the establishment of hospital functions as soon as possible. Reasonably define the government's supervisory responsibilities as a funder and the autonomous operation authority of public hospitals. Separating the health administration from the dual identity of athletes and referees, and strictly enforce its supervisory duties. The current liabilities of public hospitals in Harbin are composed of short-term loans, materials payable, etc. The Harbin Municipal Health Planning Commission should follow the principles that stock of locked debts and control debt increments, establish a strict supervision mechanism for public hospitals to resolve their own current liabilities. Preventing hospitals borrowing liquid funds to repay liabilities and turning short-term liabilities into long-term liabilities increases government burden. In addition, the health administrative department should strictly control the debt repayment planning strategy formulated by public hospitals, audit the composition of hospital assets, and ensure the liquidity of liabilities.

\section{Improve hospital internal management:}

In order to completely solve the improper liability behavior of public hospitals and improve the vitality of hospitals, Harbin public hospitals should speed up the establishment of modern hospital management system.

- Implement the president's responsibility system, implement a performance appraisal system for the president of public hospitals every year, and link the management level with the appointment and dismissal of positions.
- Professional matters are given to professional people. Establishing a system of chief accountants, strengthening budget management and cost control in public hospitals, major economic contracts must be signed by the chief accountant together with the president.

- Promote the transformation of hospital internal management from extensive to refined. Make the best use of everything. Public hospitals should integrate all medical equipment resources, improve the efficiency of the use of medical resources, avoid waste of resources, and at the same time adhere to the realization of public welfare and social welfare.

\section{REFERENCES}

[1] Jian Cao, Public Hospital Debt Solution[J],CHINA HOSPITAL CEO, 2016, 76-77.

[2] ZhiGang Sun, Establish a fair Basic Medical and Health System[J], SOCIAL SECURITY STUDIES, 2012, 4-6.

[3] XiaoHu Lu, Debt Risk Prevention and Control in Public Hospitals from the Perspective of National Audit[J], AUDIT MONTHLY, 2014 , 50-51.

[4] ShaoLong Wu, Study on Market Competition Government Responsibility and Debt of Public Hospitals in GuangDong Province[J], CNINESE PUBLIC POLICY REVIEW, 2017, 174-178.

[5] XiangXiang Wang, GuoDong Zhang, Study on the Current Situation, Problems and Countermeasures of Financial Compensation for Public Hospitals in AnHui Province[J]. ECONOMIC \& TRADE, 2016, 132

[6] Qi YiPing, MingHui Hu, Min Tao, Debt Analysis of City Public Hospitals in JiangXi Province[J], CHINESE HEALTH ECONAMICS,2017, 87-88.

[7] A 10-year Journey to ShenKang[J], CHINESE HEALTH ECONAMICS, 2015, 49-52. 